\title{
Systemic sclerosis phase III clinical trials - hope on the horizon?
}

\author{
Martin Aringer ${ }^{1}$ and Christopher P. Denton ${ }^{2}$ \\ ${ }^{1}$ University Medical Center and Faculty of Medicine Carl Gustav Carus at the TU Dresden, \\ Dresden, Germany \\ ${ }^{2}$ Centre for Rheumatology and Connective Tissue Diseases Royal Free Hospital, University \\ College London, London, UK
}

Correspondence to:

Prof. Martin Aringer

Rheumatology, Medicine III

University Medical Center TU Dresden

Fetscherstrasse 74

01307 Dresden

Germany

Martin.aringer@uniklinikum-dresden.de

Phone: +493514584422

Fax +493514585801

\begin{abstract}
While significant progress has been made in treating systemic sclerosis, many patients still have an outcome that is far from satisfactory. For the first time in history, several drugs are now in phase III randomized controlled trials. Approaches tested include the anti-B cell antibody rituximab, the anti-interleukin-6 receptor antibody tocilizumab, the antifibrotic drugs nintedanib and pirfenidone and the cannabinoid receptor mimetic lenabasum. That all these drugs are in advanced clinical trials despite the relatively low incidence of the disease therefore is good news. Not only is there realistic hope that at least some of the approaches will work, this also indicates growing industry interest, for most of the trials are company-sponsored. This review attempts to delineate the ongoing trials and to summarize the underlying evidence of these candidate systemic sclerosis drugs.
\end{abstract}

Key words: scleroderma, therapy, inflammatory, fibrotic, B cells, cytokines 
Systemic sclerosis (SSc) is arguably the most difficult to treat autoimmune rheumatic disease today. The number of drugs that are definitively helpful in treating SSc is small (1), and none of the therapeutic approaches is sufficiently safe and beneficial as of today (2), and when leaving aside pulmonary arterial hypertension, in particular.

When we look at the actual evidence from phase III trials, we have two commercial studies that showed bosentan helpful in the prophylaxis, but not healing, of SSc digital ulcers $(3 ; 4)$. We have the two Scleroderma Lung Study trials, which proved (limited) efficacy of cyclophosphamide in SSc interstitial lung disease (ILD)(5) and a similar effect of mycophenolate mofetil (MMF), respectively (6). We now have two trials showing autologous stem cell transplantation superior to cyclophosphamide, albeit at the price of significant procedure-associated early mortality $(2 ; 7)$. Finally, although not from randomized controlled trials (RCTs), we have convincing evidence for a role of angiotensin converting enzyme (ACE) inhibitors in SSc renal crisis (1). All of these trials have tremendous importance. Nevertheless, the options we can now offer our patients are partly sufficient at best.

Several reasons may together explain this lack of fully adequate therapies. In part, this is still due to insufficient understanding of SSc pathophysiology. While we understand today that SSc involves both endothelial damage and tissue fibrosis, and while we are also able to more precisely subgroup patients based on autoantibodies (8-10), the underlying mechanisms of disease are still rather hypothetical. Nevertheless, some of the insights have led to clinically testable hypotheses. Another part of the problem is the relatively low incidence of SSc, which has made larger clinical trials very difficult, which has in part been overcome by combining forces, mainly through EUSTAR, the EULAR scleroderma trials and research group (11). Also related to the low incidence is the historically limited interest of pharmaceutical companies in the disease. This issue has been partly resolved by legislation favoring orphan drugs. Accordingly, the number of advanced clinical trials is slowly increasing, and it appears worthwhile to look at the ongoing phase III trials. This manuscript attempts to point out these trials and provide background on the approaches taken.

\section{Methods}

Clinicaltrials.gov was queried for phase III controlled trials in patients with systemic sclerosis (last on February 1, 2018). These advanced clinical trials included three on biological DMARDs, namely on tocilizumab and rituximab, and three on oral drugs, namely on lenabasum, nintedanib and pirfenidone (Table 1). For each of these drugs, the published literature regarding use in systemic sclerosis or related fields was reviewed. Results were ordered by NCT numbers 


\section{Rituximab}

NCT01248084 RECOVER Sponsor: Assistance Publique - Hôpitaux des Paris

$1 \mathrm{~g}$ rituximab day 1 and 15 vs. placebo

Duration 6 (12) months

Inclusion: SSc with polyarthritis ( $\geq 4$ swollen joints)

Primary endpoint: Number of tender and swollen joints

Secondary endpoints include:

- SSc-HAQ

- $\quad$ mRSS

- FVC

NCT01862926 RECITAL

Sponsor: Royal Brompton \& Harefield NHS Foundation Trust

$1 \mathrm{~g}$ rituximab day 1 and 15 vs cyclophosphamide $600 \mathrm{mg} / \mathrm{m}^{2} \mathrm{q} 4$ weeks for $6 \mathrm{x}$

Duration 48 weeks

Inclusion: SSc or PM/DM or MCTD with ILD

Primary endpoint: Absolute change in FVC

Secondary endpoints include:

- Change in DLCO

- Change in HR-QoL

- Progression free survival

\section{Tocilizumab}

NCT02453256 focuSSced Sponsor: Hoffmann-La Roche

$162 \mathrm{mg}$ tocilizumab q week vs. placebo

Duration 48 weeks, open label extension trial

Inclusion: SSc with mRSS 10-35

Primary endpoint: Change in mRSS from week 0 to week 48

Secondary endpoints include:

- Proportion 20/40/60\% mRSS improvement

- Change in FVC

- Change in HAQ-DI

- Digital ulcers

\section{Nintedanib}

NCT02597933 SENSCIS Sponsor: Boehringer Ingelheim

Nintedanib $150 \mathrm{mg}$ bid vs. placebo

Duration 52 weeks, open label extension trial (NCT03313180)

Inclusion: SSc with ILD ( $\geq 10 \%$ on CT)

Primary endpoint: Annual rate of decline in FVC (ml)

Secondary endpoints include:

- Time to all-cause-mortality

- Change in mRSS

- Change in SHAQ

Pirfenidone

- Digital ulcers 
Pirfenidone $200 \mathrm{mg}$ tid vs. placebo

Duration: 24 weeks

Inclusion: SSc with $\mathrm{mRSS} \geq 10$

Primary endpoint: mRSS

Secondary endpoints include:

- Chest CT

- FVC

- QoL

\section{Lenabasum}

NCT03398837 RESOLVE-1 Sponsor: Corbus Pharmaceuticals Inc.

Lenabasum $5 \mathrm{mg}$ or $20 \mathrm{mg}$ bid vs. placebo

Duration 1 year

Inclusion: dcSSc

Primary endpoint: Change in mRSS

Secondary endpoints include:

- Change in HAQ-DI

- $\quad$ ACR combined response index (ACR CRISS)

- $\quad$ Change in FVC

\section{Rituximab}

Rituximab is a chimeric monoclonal antibody against $\mathrm{CD} 20$, a protein exclusively present on the surface of B cells, but not on early B cell precursors or plasma cells (12). Rituximab depletes B cells almost completely, but does not usually diminish immunoglobulin severely (13). Rituximab was first approved for B cell malignancies, but is also approved for treating rheumatoid arthritis (14) and ANCA associated vasculitides (15;16). Rituximab is marketed by Roche. The drug is out of patent and biosimilars have been approved.

There are currently two ongoing rituximab trials in systemic sclerosis, locally sponsored in France and the UK, respectively. Both trials use $1 \mathrm{~g}$ rituximab at day 1 and 15 , as in rheumatoid arthritis. The French trial RECOVER (NCT01248084) focusses on joint disease, and accordingly has the swollen and tender joint count as its primary endpoint, but also looks at forced vital capacity (FVC) and modified Rodnan's skin score (MRSS). The UK trial RECITAL (NCT01862926) has a focus on interstitial lung disease, in contrast, and also includes patients with other connective tissue diseases (CTDs), namely mixed connective tissue disease (MCTD) and inflammatory myopathies (poly- and dermatomyositis) (17). Its primary endpoint is the absolute change in FVC.

Both trials are based on sound hypotheses. Rituximab is approved for rheumatoid arthritis, but there are also observational data that it may be effective in the arthritides of CTDs (18). Likewise, there is a significant body of observational data indicating rituximab efficacy for interstitial lung disease in CTDs (19-22). Despite changes in SSc autoantibodies following rituximab (23), the main mechanism 
apparently is not downmodulation of autoantibodies. Instead, the removal of cytokine producing B cells, with reduced IL-6 shown after rituximab in SSc (24), but particularly the loss of specific antigen presentation by B cells are discussed as the main mechanisms of action. B cells are indeed present in SSc skin, and get depleted by rituximab (25), which also reduced myofibroblasts and hyalinized collagen (25), as well as fibroblast type I collagen production (26).

While there are no controlled trial data so far, rituximab use in SSc is apparently widespread, with 63 SSc patients included into a 2015 EUSTAR paper (22). This paper found indications of improved skin thickening, with MRSS falling from $27 \pm 1$ to $20 \pm 2$ in 25 rituximab-treated SSc patients, but not matched controls, and stabilization of interstitial lung disease in 9 rituximab-treated patients (with concomitant fall in the matched controls). Smaller case series also suggest positive effects on the MRSS $(21 ; 24 ; 27-$ $29)$, and an increase in FVC $(21 ; 27 ; 30)$ and DLCO $(21 ; 30)$.

\section{Tocilizumab}

Tocilizumab is a humanized monoclonal antibody against the human interleukin-6 (IL-6) receptor $\alpha$ chain (31). Tocilizumab blocks IL-6 signalling almost completely, and is approved for treating rheumatoid arthritis (32), systemic onset juvenile idiopathic arthritis (33) and giant cell arteritis (34). Tocilizumab is co-marketed by Roche and Chugai.

The ongoing phase III clinical trial focuSSced (NCT02453256) sponsored by Roche is placebocontrolled and included patients with early diffuse cutaneous SSc (dcSSc). FocuSSced has an improvement in modified Rodnan's Skin Score (mRSS) as its primary endpoint (Table 1). Key secondary endpoints include lung function tests and patient related outcome parameters.

The original idea stems from several ex vivo findings (35), and data that high amounts of IL-6 in SSc sera contain correlate with mRSS (36), in particular. In addition, higher levels of IL6 appeared to reflect poor prognosis from lung fibrosis in SSc and higher mortality (37) with more persistently severe skin sclerosis (38). Early case reports suggest rapid skin score improvement (39). The consequence was faSScinate, a phase II clinical trial. FaSScinate randomized 87 patients with dcSSc of not more than 5 years disease duration 1:1 (43:44) to a weekly $162 \mathrm{mg}$ s.c. injection of tocilizumab or a placebo injection over 48 weeks (40). The primary endpoint was the mean change in mRSS from baseline to 24 weeks. While missing the primary endpoint, there was a trend towards greater improvement in mRSS at 24 weeks (-3.92 vs. $-1.22, \mathrm{p}=0.0915)$, which approached significance at 48 weeks (-6.33 vs. -2.77 , $\mathrm{p}=0.0579$ ). Tocilizumab treated patients had a trend towards more commonly reaching $20 \% \mathrm{mRSS}$ improvement at week 24 (37\% vs. $27 \%, \mathrm{p}=0.36)$, and were significantly more likely to reach a $60 \%$ mRSS decrease $(12 \%$ vs $0 \%, p=0.026)$ or a clinically important improvement of $\geq 4.7$ units $(37 \%$ vs 
$25 \%, \mathrm{p}=0.025$ ) by week 48 . Importantly, forced vital capacity (FVC) was significantly less decreased after 24 weeks of tocilizumab than under placebo $(-34 \mathrm{~mL}$ vs. $-171 \mathrm{~mL}, \mathrm{p}=0.0368)$.

With the consecutive open-label period, $63 \%$ of the tocilizumab-treated and $55 \%$ of the placebo-treated patients completed 96 weeks (41). The patients of the tocilizumab group improved further in mRSS to -9.3 at 72 weeks and stabilized at -9.1 at 96 weeks. The patients switched from placebo to open label tocilizumab had an improvement of -5.2 units at 72 weeks and reached -9.4 , the same level of improvement as the original tocilizumab group, at week 96, after one year of tocilizumab therapy. Of the 30 patients in the tocilizumab group who finished 96 weeks, 22 (73\%) had $\geq 4.7 \mathrm{mRSS}$ units improvement, as had 19 of the 24 (79\%) of the group switched from placebo to tocilizumab. In the openlabel period no patient had a $>10 \%$ decline in FVC, as compared to 3 in the placebo group and 1 in the tocilizumab group during the placebo-controlled phase.

In total, four patients died in the placebo-controlled phase, 3 of whom were in the tocilizumab arm. However, only one of the deaths, due to pneumonia, was considered possibly treatment related. No patient died during the open label extension phase.

\section{Nintedanib}

Nintedanib is a relatively non-selective tyrosine kinase inhibitor, which inhibits the kinase activity of various growth factor receptors, including those of vascular endothelial growth factor (VEGF), fibroblast growth factor (FGF) and platelet-derived growth factor (PDGF)(42). Nintedanib is approved for treatment of idiopathic pulmonary fibrosis (IPF)(43), and is also being tested for several malignancies. Nintedanib is owned and marketed by Boehringer Ingelheim.

SENSCIS (NCT02597933), the ongoing phase III clinical trial in SSc-related lung fibrosis (44) sponsored by Boehringer Ingelheim is placebo controlled and includes patients with dcSSc, at least $10 \%$ lung fibrosis on chest $\mathrm{CT}$ and $\mathrm{FVC} \geq 40 \%$ of the predicted value. The primary endpoint is $\mathrm{mL}$ decline in FVC assessed at 52 weeks (Table 1). Secondary endpoints include other measures of lung function, time to all course mortality, SSc digital ulcers and mRSS. Cases are stratified according to the use of concurrent immunosuppression with mycophenolate mofetil or methotrexate. These agents are used as standard background therapy for systemic sclerosis in many centres, as evidenced by the recently reported European Scleroderma Observational Study (ESOS) that demonstrated improvement in skin score with both drugs after statistical adjustment for potential baseline confounding factors (45). In SENSCIS these agents should be at stable dose at the time of randomization to nintedanib or placebo.

The original hypothesis is based on similarities in lung fibrosis between IPF and SSc-interstitial lung disease. In IPF, where no treatment option other than lung transplantation had previously existed, nintedanib has been proven to not only reduce the decline in FVC, but to also actually improve survival 
(43). The IPF trials had in part been based on animal data using the bleomycin model of fibrosis (46), which is also regarded relevant to SSc pathophysiology, at least to some degree. Recently, nintedanib was also shown to ameliorate both fibrotic and vascular manifestations of Fra2-transgenic animals (47), which have manifestations rather similar to patients with dcSSc.

Since there are no SSc data available yet, we can only look at the two replicate phase III IPF studies INPULSIS-1 and 2 (48) instead. In these trials, 1,066 IPF patients were, in a 3:2 ratio, randomized to $150 \mathrm{mg}$ nintedanib b.i.d. or placebo. Reduction in FVC was significantly lower in the nintedanib than in the placebo group $(-114.7 \mathrm{~mL} /$ year vs. $-239.9 \mathrm{~mL} / \mathrm{year}, \mathrm{p}<0.001$ and $-113.6 \mathrm{~mL} / \mathrm{year}$ vs. -207.3 $\mathrm{mL} /$ year for INPULSIS-1 and 2, respectively). Of the nintedanib-treated patients, $29.5 \%$ had more than $10 \%$ FVC decline, as compared to $36.8 \%$ under placebo.

A total of 68 patients died in the two trials, $37(5.8 \%)$ in the nintedanib and $31(7.3 \%)$ in the placebo arms. Adverse events leading to treatment discontinuation were more common under nintedanib, mostly diarrheas (7.3\%) and liver enzyme elevations.

\section{Pirfenidone}

Pirfenidone is the other drug approved for IPF $(49 ; 50)$, which is co-marketed by Intermune, Shionigi and Cipla. Pirfenidone was shown to in vitro influence TGF $\beta$ and TNF activity and to inhibit fibroblast proliferation and collagen synthesis (51). While the exact mechanisms are still not sufficiently clear, pirfenidone inhibits TGF $\beta$ induced transcription factors of the glioma-associated oncogene homolog (GLI) group in the downstream hedgehog (Hh) signaling pathway (52). Possibly downstream of this effect, pirfenidone suppresses MAPK signaling (53)and expression of chemokine ligand-2 (CCL-2)(54) and of inter-cellular adhesion molecule-1 (ICAM-1)(55).

The ongoing 24 week trial NCT03068234 locally performed in Shanghai, China, is testing pirfenidone primarily for its efficacy on SSc skin, with mRSS as the primary endpoint. However, interstitial lung disease is looked at in several secondary endpoints, and FVC and chest CT, in particular. Formally a phase II trial, the placebo-controlled Scleroderma Lung Study III (NCT03221257) will compare MMF with pirfenidone (801 $\mathrm{mg}$ tid) against MMF alone. The primary endpoint is the change in FVC; secondary endpoints include chest CTs, mRSS and SHAQ. In addition, a combined non-IPF lung fibrosis trial, RELIEF (DRKS00009822), is intended to also include patients with SSc interstitial lung disease (56).

Like with nintedanib, the hypotheses are based on the anti-fibrotic effects and similarities between SSc lung disease and IPF, and pirfenidone effects on bleomycin-induced pulmonary fibrosis (54). For IPF, the two CAPACITY trials (51) and the ASCEND trial (50) showed efficacy in reducing disease 
progression. A metaanalysis of the three trials also demonstrated improved progression-free survival (49).

LOTUSS, a small, 16 week open label phase II trial of pirfenidone in patients with SSc interstitial lung disease (57), mostly (66\%) in combination with MMF, mainly analyzed safety. Patients were randomized 1:1 to a faster (weekly increments) and a slower (biweekly increments) titration to the full $801 \mathrm{mg}$ tid dose. Of the 32 patients in the rapid titration arm 5 (16\%) stopped because of treatmentemergent adverse events, as compared to $1 / 31(3 \%)$ in the slow titration arm. The most common severe treatment-emergent adverse events were fatigue (5\%), diarrhea (3\%) and nausea (3\%). No lifethreatening events occurred, and no patients died. No relevant changes in MRSS or FVC could be demonstrated. The Scleroderma Lund Study III will accordingly use the slow titration protocol.

\section{Lenabasum}

Lenabasum (formerly anabasum) is an endocannabinoid mimetic drug owned by Corbus Pharmaceuticals. Lenabasum is a synthetic analog of $\Delta 8$-tetrahydrocannabinol-11-oic acid, which selectively binds the $\mathrm{CB} 2$ receptor on activated immune cells, and thus has minimal effects on the central nervous system (58). Lower doses of lenabasum (5 mg) inhibit the neutrophil chemoattractant leukotriene B4 and inflammatory prostanoids (prostaglandin E2 and F2 $\alpha$ as well as Thromboxane B2), approximately equal to $15 \mathrm{mg}$ prednisolon. Higher doses $(20 \mathrm{mg})$ also increased lipid mediators that are thought to resolve inflammation, namely lipoxin A4, lipoxin B4, resolvin D1 and resolvin D3. Lenabasum is thought to resolve chronic inflammatory and fibrotic processes.

The one year RESOLVE-1 SSc trial (NCT03398837) sponsored by Corbus Pharmaceuticals tests $5 \mathrm{mg}$ and $20 \mathrm{mg}$ lenabasum against placebo. The primary endpoint is change in mRSS, but secondary endpoints include change in FVC, change in HAQ-DI and the ACR combined response index (ACR CRISS).

A 16 week double-blind phase 2 study of the efficacy of lenabasum was so far published in abstract form only (59). Of 42 patients with dcSSc included, 27 received lenabasum and 15 placebo. By ACR CRISS, anabasum treated patients had significantly greater improvement. No serious adverse events occurred.

\section{Conclusions}

There are ongoing discussions on how to best perform SSc clinical trials. Trials might better focus on specific autoantibody subsets and on early dcSSc, where prediction models derived from large cohorts could help to exclude patients with high placebo response rates $(60 ; 61)$. Nevertheless, current trial 
protocols have been successful in showing differences, and have influence those of ongoing studies. While no final results are available yet on any of these clinical trials, it appears reassuring that so many different approaches are currently being tested in phase III randomized clinical trials in SSc patients. That potential therapies have moved to phase III evaluation is testament to the success of these agents in treating other potentially related diseases such as idiopathic pulmonary fibrosis (IPF) or in the case of tocilizumab and lenabasum success at phase II of clinical development programmes in SSc. The majority of substances are grounded in a better understanding of SSc pathophysiology, and many of them have already shown impressive efficacy in related fields. All of the drugs have in essence antiinflammatory and secondary anti-fibrotic effects. Given both that immunosuppressive approaches, including autologous stem cell therapy, have so far only shown limited effects, and that we are not able so far to eliminate SSc autoantibodies, this kind of approach presumably has the best chance today. Accordingly, there are good reasons to hope that we will be able to offer SSc patients more effective and fairly safe medications in the near future. 
Table 2. Overview of mechanisms of action in current phase III SSc trials.

\begin{tabular}{|c|c|c|c|c|c|}
\hline \multicolumn{3}{|c|}{ Approach } & Drug & Mechanism of Action & Proven Effects \\
\hline Cellular & \multirow{5}{*}{ 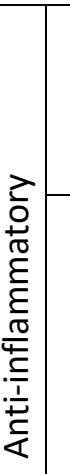 } & \multirow{5}{*}{ 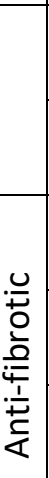 } & Rituximab & Anti-CD20 antibody & $\begin{array}{l}\text { B cell depletion } \\
\text { IL- } 6 \text { reduction }\end{array}$ \\
\hline & & & Tocilizumab & Anti-IL-6R antibody & $\begin{array}{l}\text { IL-6R blockade } \\
\text { Reduction fibroblast activation }\end{array}$ \\
\hline & & & Lenabasum & Cannabinoid-R CB2 mimetic & $\begin{array}{l}\text { Decrease prostanoids } \\
\text { Increase resolvins } \\
\end{array}$ \\
\hline & & & Nintedanib & Tyrosine kinase inhibitor & $\begin{array}{l}\text { VEGF-R, FGF-R, PDGF-R activation } \\
\text { blockade }\end{array}$ \\
\hline & & & Pirfenidone & & $\begin{array}{l}\text { Inhibited fibroblast proliferation } \\
\text { Inhibited collagen synthesis }\end{array}$ \\
\hline
\end{tabular}

\section{Reference List}

(1) Kowal-Bielecka O, Fransen J, Avouac J, Becker M, Kulak A, Allanore Y et al. Update of EULAR recommendations for the treatment of systemic sclerosis. Ann Rheum Dis 2017; 76(8):132739.

(2) Sullivan KM, Goldmuntz EA, Keyes-Elstein L, McSweeney PA, Pinckney A, Welch B et al. Myeloablative Autologous Stem-Cell Transplantation for Severe Scleroderma. N Engl J Med 2018; 378(1):35-47.

(3) Korn JH, Mayes M, Matucci CM, Rainisio M, Pope J, Hachulla E et al. Digital ulcers in systemic sclerosis: prevention by treatment with bosentan, an oral endothelin receptor antagonist. Arthritis Rheum 2004; 50(12):3985-93.

(4) Matucci-Cerinic M, Denton CP, Furst DE, Mayes MD, Hsu VM, Carpentier P et al. Bosentan treatment of digital ulcers related to systemic sclerosis: results from the RAPIDS-2 randomised, double-blind, placebo-controlled trial. Ann Rheum Dis 2011; 70(1):32-8.

(5) Tashkin DP, Elashoff R, Clements PJ, Goldin J, Roth MD, Furst DE et al. Cyclophosphamide versus placebo in scleroderma lung disease. N Engl J Med 2006; 354(25):2655-66.

(6) Tashkin DP, Roth MD, Clements PJ, Furst DE, Khanna D, Kleerup EC et al. Mycophenolate mofetil versus oral cyclophosphamide in scleroderma-related interstitial lung disease (SLS II): a randomised controlled, double-blind, parallel group trial. Lancet Respir Med 2016; 4(9):70819.

(7) van Laar JM, Farge D, Sont JK, Naraghi K, Marjanovic Z, Larghero J et al. Autologous hematopoietic stem cell transplantation vs intravenous pulse cyclophosphamide in diffuse cutaneous systemic sclerosis: a randomized clinical trial. JAMA 2014; 311(24):2490-8.

(8) Gabrielli A, Avvedimento EV, Krieg T. Scleroderma. N Engl J Med 2009; 360(19):1989-2003.

(9) Nihtyanova SI, Denton CP. Autoantibodies as predictive tools in systemic sclerosis. Nat Rev Rheumatol 2010; 6(2):112-6. 
(10) Koenig M, Dieude M, Senecal JL. Predictive value of antinuclear autoantibodies: the lessons of the systemic sclerosis autoantibodies. Autoimmun Rev 2008; 7(8):588-93.

(11) Muller-Ladner U, Tyndall A, Czirjak L, Denton C, Matucci-Cerinic M. Ten years EULAR Scleroderma Research and Trials (EUSTAR): what has been achieved? Ann Rheum Dis 2014; 73(2):324-7.

(12) Dorner T, Kinnman N, Tak PP. Targeting B cells in immune-mediated inflammatory disease: a comprehensive review of mechanisms of action and identification of biomarkers. Pharmacol Ther 2010; 125(3):464-75.

(13) van Vollenhoven RF, Fleischmann RM, Furst DE, Lacey S, Lehane PB. Longterm Safety of Rituximab: Final Report of the Rheumatoid Arthritis Global Clinical Trial Program over 11 Years. J Rheumatol 2015; 42(10):1761-6.

(14) Edwards JC, Szczepanski L, Szechinski J, Filipowicz-Sosnowska A, Emery P, Close DR et al. Efficacy of B-cell-targeted therapy with rituximab in patients with rheumatoid arthritis. $\mathrm{N}$ Engl J Med 2004; 350(25):2572-81.

(15) Stone JH, Merkel PA, Spiera R, Seo P, Langford CA, Hoffman GS et al. Rituximab versus cyclophosphamide for ANCA-associated vasculitis. N Engl J Med 2010; 363(3):221-32.

(16) Jones RB, Tervaert JW, Hauser T, Luqmani R, Morgan MD, Peh CA et al. Rituximab versus cyclophosphamide in ANCA-associated renal vasculitis. N Engl J Med 2010; 363(3):211-20.

(17) Saunders P, Tsipouri V, Keir GJ, Ashby D, Flather MD, Parfrey $\mathrm{H}$ et al. Rituximab versus cyclophosphamide for the treatment of connective tissue disease-associated interstitial lung disease (RECITAL): study protocol for a randomised controlled trial. Trials 2017; 18(1):275.

(18) Aringer M, Burkhardt H, Burmester GR, Fischer-Betz R, Fleck M, Graninger W et al. Current state of evidence on "off label" therapeutic options for systemic lupus erythematosus, including biological immunosuppressive agents, in Germany, Austria, and Switzerland - a consensus report. Lupus 2012; 21(4):386-401.

(19) Aringer $M$, Burkhardt $H$, Burmester GR, Fischer-Betz R, Fleck $M$, Graninger $W$ et al. Current state of evidence on 'off-label' therapeutic options for systemic lupus erythematosus, including biological immunosuppressive agents, in Germany, Austria and Switzerland--a consensus report. Lupus 2012; 21(4):386-401.

(20) Daoussis D, Liossis SN, Tsamandas AC, Kalogeropoulou C, Paliogianni F, Sirinian C et al. Effect of long-term treatment with rituximab on pulmonary function and skin fibrosis in patients with diffuse systemic sclerosis. Clin Exp Rheumatol 2012; 30(2 Suppl 71):S17-S22.

(21) Moazedi-Fuerst FC, Kielhauser SM, Brickmann K, Hermann J, Lutfi A, Meilinger M et al. Rituximab for systemic sclerosis: arrest of pulmonary disease progression in five cases. Results of a lower dosage and shorter interval regimen. Scand J Rheumatol 2014; 43(3):257-8.

(22) Jordan S, Distler JH, Maurer B, Huscher D, van Laar JM, Allanore $Y$ et al. Effects and safety of rituximab in systemic sclerosis: an analysis from the European Scleroderma Trial and Research (EUSTAR) group. Ann Rheum Dis 2015; 74(6):1188-94.

(23) Bonroy C, Smith V, Deschepper E, de KF, Devreese K. Specific Antinuclear Antibody Level Changes after B Cell Depletion Therapy in Systemic Sclerosis Are Associated with Improvement of Skin Thickening. J Rheumatol 2016; 43(1):247-9. 
(24) Bosello S, De SM, Lama G, Spano C, Angelucci C, Tolusso B et al. B cell depletion in diffuse progressive systemic sclerosis: safety, skin score modification and IL-6 modulation in an up to thirty-six months follow-up open-label trial. Arthritis Res Ther 2010; 12(2):R54.

(25) Smith V, van Praet JT, Vandooren B, Van der Cruyssen B, Naeyaert JM, Decuman S et al. Rituximab in diffuse cutaneous systemic sclerosis: an open-label clinical and histopathological study. Ann Rheum Dis 2010; 69(1):193-7.

(26) Fraticelli P, De VS, Franzolini N, Svegliati S, Scott CA, Tonnini C et al. Reduced type I collagen gene expression by skin fibroblasts of patients with systemic sclerosis after one treatment course with rituximab. Clin Exp Rheumatol 2015; 33(4 Suppl 91):S160-S167.

(27) Daoussis D, Melissaropoulos K, Sakellaropoulos G, Antonopoulos I, Markatseli TE, Simopoulou $T$ et al. A multicenter, open-label, comparative study of B-cell depletion therapy with Rituximab for systemic sclerosis-associated interstitial lung disease. Semin Arthritis Rheum 2017; 46(5):625-31.

(28) Giuggioli D, Lumetti F, Colaci M, Fallahi P, Antonelli A, Ferri C. Rituximab in the treatment of patients with systemic sclerosis. Our experience and review of the literature. Autoimmun Rev 2015; 14(11):1072-8.

(29) Smith V, Piette Y, van Praet JT, Decuman S, Deschepper E, Elewaut D et al. Two-year results of an open pilot study of a 2-treatment course with rituximab in patients with early systemic sclerosis with diffuse skin involvement. J Rheumatol 2013; 40(1):52-7.

(30) Daoussis D, Liossis SN, Tsamandas AC, Kalogeropoulou C, Kazantzi A, Sirinian C et al. Experience with rituximab in scleroderma: results from a 1-year, proof-of-principle study. Rheumatology (Oxford) 2010; 49(2):271-80.

(31) Nishimoto N, Kishimoto T. Interleukin 6: from bench to bedside. Nat Clin Pract Rheumatol 2006; 2(11):619-26.

(32) Smolen JS, Beaulieu A, Rubbert-Roth A, Ramos-Remus C, Rovensky J, Alecock E et al. Effect of interleukin-6 receptor inhibition with tocilizumab in patients with rheumatoid arthritis (OPTION study): a double-blind, placebo-controlled, randomised trial. Lancet 2008; 371(9617):987-97.

(33) Brunner HI, Ruperto N, Zuber Z, Keane C, Harari O, Kenwright A et al. Efficacy and safety of tocilizumab in patients with polyarticular-course juvenile idiopathic arthritis: results from a phase 3, randomised, double-blind withdrawal trial. Ann Rheum Dis 2015; 74(6):1110-7.

(34) Stone JH, Tuckwell K, Dimonaco S, Klearman $M$, Aringer $M$, Blockmans $D$ et al. Trial of Tocilizumab in Giant-Cell Arteritis. N Engl J Med 2017; 377(4):317-28.

(35) Muangchan C, Pope JE. Interleukin 6 in systemic sclerosis and potential implications for targeted therapy. J Rheumatol 2012; 39(6):1120-4.

(36) Sato S, Hasegawa M, Takehara K. Serum levels of interleukin- 6 and interleukin-10 correlate with total skin thickness score in patients with systemic sclerosis. J Dermatol Sci 2001; $27(2): 140-6$.

(37) De LA, Sestini P, Pantelidis P, Hoyles R, Hansell DM, Goh NS et al. Serum interleukin 6 is predictive of early functional decline and mortality in interstitial lung disease associated with systemic sclerosis. J Rheumatol 2013; 40(4):435-46. 
(38) Khan K, Xu S, Nihtyanova S, Derrett-Smith E, Abraham D, Denton CP et al. Clinical and pathological significance of interleukin 6 overexpression in systemic sclerosis. Ann Rheum Dis 2012; 71(7):1235-42.

(39) Abe K, Takasaki Y, Ushiyama C, Asakawa J, Fukazawa T, Seki M et al. Expression of CD80 and CD86 on peripheral blood T lymphocytes in patients with systemic lupus erythematosus. J Clin Immunol 1999; 19(1):58-66.

(40) Khanna D, Denton CP, Jahreis A, van Laar JM, Frech TM, Anderson ME et al. Safety and efficacy of subcutaneous tocilizumab in adults with systemic sclerosis (faSScinate): a phase 2, randomised, controlled trial. Lancet 2016; 387(10038):2630-40.

(41) Khanna D, Denton CP, Lin CJF, van Laar JM, Frech TM, Anderson ME et al. Safety and efficacy of subcutaneous tocilizumab in systemic sclerosis: results from the open-label period of a phase II randomised controlled trial (faSScinate). Ann Rheum Dis 2018; 77(2):212-20.

(42) Richeldi L, Costabel U, Selman M, Kim DS, Hansell DM, Nicholson AG et al. Efficacy of a tyrosine kinase inhibitor in idiopathic pulmonary fibrosis. N Engl J Med 2011; 365(12):1079-87.

(43) Richeldi L, Cottin V, du Bois RM, Selman M, Kimura T, Bailes Z et al. Nintedanib in patients with idiopathic pulmonary fibrosis: Combined evidence from the TOMORROW and INPULSIS((R)) trials. Respir Med 2016; 113:74-9.

(44) Distler O, Brown KK, Distler JHW, Assassi S, Maher TM, Cottin V et al. Design of a randomised, placebo-controlled clinical trial of nintedanib in patients with systemic sclerosis-associated interstitial lung disease (SENSCIS). Clin Exp Rheumatol 2017; 35 Suppl 106(4):75-81.

(45) Herrick AL, Pan X, Peytrignet S, Lunt M, Hesselstrand R, Mouthon L et al. Treatment outcome in early diffuse cutaneous systemic sclerosis: the European Scleroderma Observational Study (ESOS). Ann Rheum Dis 2017; 76(7):1207-18.

(46) Chaudhary NI, Roth GJ, Hilberg F, Muller-Quernheim J, Prasse A, Zissel G et al. Inhibition of PDGF, VEGF and FGF signalling attenuates fibrosis. Eur Respir J 2007; 29(5):976-85.

(47) Huang J, Maier C, Zhang Y, Soare A, Dees C, Beyer C et al. Nintedanib inhibits macrophage activation and ameliorates vascular and fibrotic manifestations in the Fra2 mouse model of systemic sclerosis. Ann Rheum Dis 2017; 76(11):1941-8.

(48) Richeldi L, du Bois RM, Raghu G, Azuma A, Brown KK, Costabel U et al. Efficacy and safety of nintedanib in idiopathic pulmonary fibrosis. N Engl J Med 2014; 370(22):2071-82.

(49) Noble PW, Albera C, Bradford WZ, Costabel U, du Bois RM, Fagan EA et al. Pirfenidone for idiopathic pulmonary fibrosis: analysis of pooled data from three multinational phase 3 trials. Eur Respir J 2016; 47(1):243-53.

(50) King TE, Jr., Bradford WZ, Castro-Bernardini S, Fagan EA, Glaspole I, Glassberg MK et al. A phase 3 trial of pirfenidone in patients with idiopathic pulmonary fibrosis. N Engl J Med 2014; 370(22):2083-92.

(51) Noble PW, Albera C, Bradford WZ, Costabel U, Glassberg MK, Kardatzke D et al. Pirfenidone in patients with idiopathic pulmonary fibrosis (CAPACITY): two randomised trials. Lancet 2011; 377(9779):1760-9. 
(52) Didiasova M, Singh R, Wilhelm J, Kwapiszewska G, Wujak L, Zakrzewicz D et al. Pirfenidone exerts antifibrotic effects through inhibition of GLI transcription factors. FASEB J 2017; 31(5):1916-28.

(53) Li Z, Liu X, Wang B, Nie Y, Wen J, Wang Q et al. Pirfenidone suppresses MAPK signalling pathway to reverse epithelial-mesenchymal transition and renal fibrosis. Nephrology (Carlton ) 2017; 22(8):589-97.

(54) Inomata M, Kamio K, Azuma A, Matsuda K, Kokuho N, Miura Y et al. Pirfenidone inhibits fibrocyte accumulation in the lungs in bleomycin-induced murine pulmonary fibrosis. Respir Res 2014; 15:16.

(55) Kaneko M, Inoue H, Nakazawa R, Azuma N, Suzuki M, Yamauchi S et al. Pirfenidone induces intercellular adhesion molecule-1 (ICAM-1) down-regulation on cultured human synovial fibroblasts. Clin Exp Immunol 1998; 113(1):72-6.

(56) Behr J, Neuser P, Prasse A, Kreuter M, Rabe K, Schade-Brittinger C et al. Exploring efficacy and safety of oral Pirfenidone for progressive, non-IPF lung fibrosis (RELIEF) - a randomized, double-blind, placebo-controlled, parallel group, multi-center, phase II trial. BMC Pulm Med 2017; 17(1):122.

(57) Khanna D, Albera C, Fischer A, Khalidi N, Raghu G, Chung L et al. An Open-label, Phase II Study of the Safety and Tolerability of Pirfenidone in Patients with Scleroderma-associated Interstitial Lung Disease: the LOTUSS Trial. J Rheumatol 2016; 43(9):1672-9.

(58) Motwani MP, Bennett F, Norris PC, Maini AA, George MJ, Newson J et al. Potent AntiInflammatory and Pro-Resolving Effects of Anabasum in a Human Model of Self-Resolving Acute Inflammation. Clin Pharmacol Ther 2017.

(59) Spiera R, Hummers L, Chung L, Frech T, Domsic R, Furst D et al. A phase 2 study of safety and efficacy of anabasum (JBT-101) in systemic sclerosis. Ann Rheum Dis 2017; 76(Suppl 2): 105. ( Abstract)

(60) Dobrota R, Maurer B, Graf N, Jordan S, Mihai C, Kowal-Bielecka O et al. Prediction of improvement in skin fibrosis in diffuse cutaneous systemic sclerosis: a EUSTAR analysis. Ann Rheum Dis 2016; 75(10):1743-8.

(61) Herrick AL, Peytrignet S, Lunt M, Pan X, Hesselstrand R, Mouthon L et al. Patterns and predictors of skin score change in early diffuse systemic sclerosis from the European Scleroderma Observational Study. Ann Rheum Dis 2018; 77(4):563-70. 